\title{
La necesidad de abandonar o reformular la Ley Modelo de Insolvencia Familiar en el abordaje del sobreendeudamiento de la persona humana
}

\author{
The need to abandon or reformulate the Model \\ Law on Family Insolvency in addressing the over- \\ indebtedness of the buman person
}

\author{
Ezequiel Rodrigo Galván ${ }^{1}$ \\ Universidad Nacional de La Plata - Argentina
}

Revista Derechos en Acción ISSN 2525-1678/ e-ISSN 2525-1686

Año 5/No 17 Primavera 2020 (21 septiembre a 20 diciembre), 626-642

DOl: https://doi.org/10.24215/25251678e471

Recibido: 01/08/2020

Aprobado: 15/11/2020

Resumen: La crisis económica consecuencia del COVID-19 expone la mora estatal en implementar medidas para abordar la situación de sobreendeudamiento de la persona humana, especialmente respecto de la protección de la dignidad de la persona y de su grupo familiar. Con este motivo, las iniciativas legislativas S-1061/20 y 3540-D-2020 con el patrocinio de algunas asociaciones de consumidores se presentan como una propuesta superadora, que en la práctica implica el reingreso al Congreso nacional de la Ley Modelo de Insolvencia Familiar de la Oficina para América Latina y el Caribe de Consumers International, la cual propone un abordaje con una concepción moralista del endeudamiento

\footnotetext{
1 Abogado (UNLP). Escribano (UNLP). Diplomado en Derechos Económicos, Sociales y Culturales. Alumno de la Maestría en Derechos Humanos (UNLP). Alumno de la Diplomatura en Derechos del Consumidor y Procesos Protectorios (UNA). Alumno de la Diplomatura en Derecho Parlamentario (UA). Mail ezequielrgalvan@gmail.com (ORCID: https://orcid.org/ 0000-0003-0833-4366).
} 
personal excesivo. Siendo que este enfoque tiene consecuencias en el alcance y contenido de la tutela, así como ignora la responsabilidad estatal y/o de los proveedores de crédito y financiación para consumo, se propone abandonar concepciones binarias del sobreendeudamiento (pasivo/activo), así como reformular estas iniciativas bajo el principio rector del respeto a la dignidad de la persona.

Palabras clave: Consumidor - dignidad - derechos humanos - legislación.

Abstract: The economic crisis as a result of COVID-19 exposes the state delay in implementing measures to address the situation of over-indebtedness of the human person, especially with respect to the protection of the dignity of the person and his family group. For this reason, legislative initiatives S-1061/20 and 3540-D-2020 with the sponsorship of some consumer associations are presented as an overcoming proposal, which in practice implies the re-entry into the national Congress of the Family Insolvency Model Law of the Office for Latin America and the Caribbean of Consumers International, which proposes an approach with a moralistic conception of excessive personal indebtedness. Since this approach has consequences on the scope and content of the guardianship, as well as ignoring the state responsibility and / or responsibility of the providers of credit and consumer finance, it is proposed to abandon binary conceptions of over-indebtedness (passive / active), as well as to reformulate these initiatives under the guiding principle of respect for the dignity of the person.

Keywords: Consumer - dignity - human rights - legislation

\section{Introducción}

Si bien la crisis económica como consecuencia del COVID19 genera situaciones de sobreendeudamiento, así como preocupación del cuerpo legislativo, el sobreendeudamiento es un fenómeno que perjudica la calidad de vida y satisfacción de los derechos fundamentales de la persona humana y su grupo familiar (Japaze, 2015) respecto del cual había una necesidad preexistente de abordaje estatal ante la ausencia de mecanismos idóneos de recomposición (Rossi, 2017). En este sentido, si bien se han presentado números iniciativas legislativas con el objeto 
de dar respuestas a las familias en esta situación, el presente trabajo tiene por objeto el análisis de la "Ley Modelo de Insolvencia Familiar" que reingresa en el Congreso de la Nación bajo el proyecto S-1061/20 y 3540-D-2020 apelando al contexto producto de la pandemia.

La "Ley Modelo de Insolvencia Familiar" (2011) pertenece a la Oficina para América Latina y el Caribe de Consumers International, una federación internacional de asociaciones de usuarios y consumidores, la cual se ha proyectado en el ámbito local a través de proyectos de ley que se limitan a la transcripción de la ley modelo, siempre con el patrocinio de asociaciones de consumidores. En este aspecto, la particularidad de este proyecto, además de la legitimidad que puede atribuirle el apoyo explícito de algunas asociaciones de consumidores, está dada por una concepción de fuerte reproche moral a la persona en situación de sobreendeudamiento, así como por el retorno al "sobreendeudamiento pasivo/activo" como dirimente de la tutela.

En consecuencia, si entendemos que en el sobreendeudamiento existe una afectación a la dignidad de la persona y su grupo familiar, la respuesta estatal convencional y constitucionalmente no puede limitarse a un mecanismo de reestructuración de pasivo que asegure el cumplimiento de las obligaciones contraídas, sino que necesariamente debe tener por objeto resguardo y tutela de la dignidad de la persona más allá de los mecanismos que implemente. De este modo, el contenido y concepción de la respuesta estatal (legislativa) no se limita a ser una cuestión de calidad en la técnica legislativa (también importante), sino que tiene consecuencias directas en la construcción del sujeto de tutela y el alcance de la misma.

Siendo que existe una mora estatal que demanda un abordaje inmediato, agravado por el impacto social y económico producto de la pandemia, la persistencia de la ley modelo en nuestro debate legislativo implica la permanencia de ideas incompatibles con una tutela que priorice la protección de la dignidad humana, la prevención de la exclusión económica y social, así 
como del crédito responsable (Sánchez Cannavó, 2018) como obligación concreta de los proveedores de crédito y financiamiento.

\section{La Ley Modelo de Insolvencia Familiar y su ingreso en el Congreso de la Nación Argentina}

La Ley Modelo de Insolvencia Familiar se formula en la Oficina para América Latina y el Caribe de Consumers International en 2011, y su texto se proyecta en el ámbito nacional sin modificaciones sustanciales a través del proyecto S-0586/12 por las gestiones de la asociación de consumidores UNIÓN DE CONSUMIDORES DE ARGENTINA, y reingresos bajo las iniciativas S-0030/14, más recientemente S-1061/2020 y 3540-D-2020 con el patrocinio de las asociaciones de consumidores ADELCO, ADECUA y CRUZADA CÍVICA.

En cuanto a los mecanismos propuestos, desde su origen la iniciativa se estructura como un sistema de renegociación de deudas no comerciales ante la "insolvencia" en una instancia administrativa perjudicial de conciliación, y una instancia judicial con capacidad de imponer un plan de reestructuración del pasivo oponible a los acreedores aun sin acuerdo, e incluso un plan de liquidación si lo entendemos como una de sus modalidades tácitas. Así mismo, se complementa con referencia a planes de educación financiera y el reconocimiento de algunos derechos a los usuarios y consumidores vinculados a la prevención del sobreendeudamiento (acceso previo al contrato y acceso al estado actual de deuda a efectos de cancelarlo).

Como primera cuestión, siendo que estamos ante una ley modelo internacional cuya redacción resulta ajena a nuestra legislación local, la iniciativa incorpora definiciones propias de "persona consumidora de productos, bienes y/o servicios", "insolvencia", "entidad financiera", "tarjeta de crédito" y "bancos comerciales" ya existentes en la legislación vigente ${ }^{2}$. Así

2 Si bien estas deficiencias se encuentran presentes en el proyecto 7482-D-2010 que recupera la Ley Modelo su elaboración las profundiza. 
mismo, tampoco regula en el marco de la relación de consumo en pos de una concepción regresiva que se circunscribe al mero vínculo contractual, que se agrava desde su reingreso como el proyecto S-1061/20 y 3540-D-202020 al establecer a la ley 24.240 y la restante normativa que se integra al estatuto de los usuarios y consumidores resulta de aplicación supletoria y restrictiva ${ }^{3}$.

En consecuencia, la ausencia de adecuación a la legislación local al momento de su ingreso en el Congreso, agravado por la reforma que implicó el Código Civil y Comercial y las modificaciones en demás legislación (ley 26.994), implica que de por sí la iniciativa resulte asistemática respecto de nuestro ordenamiento jurídico, a lo cual se suman las inconsistencias internas producto de esta construcción de conceptos y definiciones constantes ${ }^{4}$.

Como segunda cuestión, en el proyecto subyace un claro entendimiento moralista de la problemática, así como simplista y binario (Japaze, 2015) que se observa manifiesto en una tutela circunscripta al "sobreendeudamiento pasivo", cuya consecuencia directa implica denegar la protección estatal ante el sobreendeudamiento de un gran espectro de personas, así como a su grupo familiar. En este aspecto, si bien el proyecto confunde reiteradamente el "sobreendeudamiento" con la "insolvencia" aun cuando no son conceptos asimilables, se restringe el reconocimiento estatal al endeudamiento de "situaciones imprevistas" o "previstas que no han podido evitarse".

Si bien el sobreendeudamiento es un concepto situado (ej. Dictamen del Comité Económico y Social Europeo "Protección de los consumidores y tratamiento adecuado del sobreendeudamiento para evitar la exclusión social" 2014, p. 3.1), existe consenso académico respecto que no resulta asimilable al concepto de "insolvencia" (Japaze, 2015), el cual además de contener un

3 “Art. 42. En todo lo que no esté explícitamente expresando en la presente ley, será de aplicación supletoria la Ley de Defensa del Consumidor 24.240".

4 Ej. la regulación del sobreendeudamiento cuando se establece la insolvencia como requisito para instar el procedimiento administrativo. 
significado atribuido por el derecho concursal, también sostiene una concepción empresaria que resulta inidónea para la tutela de la persona usuaria o consumidora (Kalafatich, 2019).

Por otro lado, desde su redacción inicial para instar el procedimiento administrativo prejudicial se expresa "siempre que su situación patrimonial sea de insolvencia"5, que además debe concurrir que sea "producto de alguna de las siguientes causas:

a) Pérdida de empleo por despido directo y/o indirecto;

b) Precariedad de empleo o empleo no registrado;

c) Incapacidad temporal o permanente;

d) Enfermedad grave o crónica que implique un gasto excesivo en tratamientos $y / 0$ medicamentos;

e) Separación personal, divorcio vincular o disolución de la sociedad conyugal;

f) Fallecimiento de uno de los cónyuges o concubino;

g) Asunción de gastos imprevistos producto de coyunturas especiales."

Cómo se puede observar, las únicas causales contempladas son de carácter ajenas al control de la persona en situación de insolvencia o sobreendeudamiento pasivo, o bien similares a un "estado de necesidad" (ej. enfermedad grave, "coyunturas especiales"), requisitos calificados que no tienen correlato alguno con los requisitos que le impone la legislación concursal a una persona jurídica, o persona empresaria para promover un proceso para reestructurar su pasivo (arts. 1, 2 y cc. ley 24.522) ${ }^{6}$.

\footnotetext{
5 De una lectura sistemática del articulado también el sobreendeudamiento pasivo habilita a instar el procedimiento si concurre con alguna de las causas enunciadas.

6 Se destaca que el reproche al endeudamiento o administración irresponsable que se le imputa a la persona no empresaria no se encuentra presente respecto de las personas físicas o jurídicas que quiebran en el marco de la actividad empresaria organizada, en la cual el profesionalismo es un rasgo distintivo, aun cuando en ocasiones hay un responsabilidad mayor (consiente o dolosa), así como consecuencias sociales de mayor impacto: créditos laborales por despidos o accidentes de trabajo, indemnización a usuarios y consumidores,
} 
En este aspecto, los efectos prácticas de esta norma es la exclusión de las personas que pueden acceder a esta vía de restructuración de pasivo sea por un sobreendeudamiento no pasivo, o una insolvencia o sobreendeudamiento pasivo con causa ajena a las enumeradas ${ }^{7}$. De igual modo, se explicita esta concepción de tutela restringida a la persona "de buena fe", y con cierta capacidad de pago, pues se reconoce la facultad discrecional del magistrado para rechazar la acción "ser inconducente, improcedente o no llenar el cometido y alcance exigido en esta clase de procesos;", contemplando la imposición de multas o sanciones a la persona deudora, la cual también se aplican cuando "pueda cumplimentar sus obligaciones y saldar la deuda en forma anticipada", situación que entendemos de procedencia excepcional, pero que se encuentra plasmada y faculta al acreedor a peticionarla.

Así mismo, el análisis de la situación del deudor a efectos de observar si puede continuar calificando como "sujeto de tutela" resulta continuo, incluso en la etapa de cumplimiento del acuerdo o plan de reestructuración de deudas (ej. "art. 38... causales de inconducta: ... obtención de nuevos préstamos (...) no avalados judicialmente"), con la exigibilidad del monto total de las cuotas pendientes ante la inconducta, solución que además de imponer un tutor judicial para cualquier acto de financiamiento o crédito, también implica un agravamiento de la situación de sobreendeudamiento ${ }^{8}$.

créditos fiscales (impuestos o seguridad social), por nombrar algunos, exponiendo el carácter injustificado de un abordaje moralizante del sobreendeudamiento.

7 Puede observarse en la enumeración de estas causales el carácter foráneo de la Ley Modelo de Insolvencia Familiar, así como la falta de adecuación en su ingreso en el Congreso Nacional, en que no contemple las consecuencias de los procesos inflacionarios recurrentes, incluso cuando en el reingreso bajo el proyecto S-1061/20 y 3540-D-2020 se alude expresamente a Ios créditos con cláusula UVA (indexación por CER). En este caso particular no estaríamos ante una "asunción de gastos imprevistos" atento a ser una obligación asumida previamente, así como salvando el efecto particular de la pandemia, nuestra jurisprudencia ha sido reticente a entender el proceso inflacionario como evento no previsible o extraordinario.

8 No se contempla la nulidad del acuerdo o el plan de reestructuración, sino la exigibilidad de los créditos en las condiciones de cumplimiento. Además de agravar la situación de sobreendeudamiento al implicar el colapso patrimonial y eventual quiebra, también fomenta 
Cómo última cuestión, aun ignorando los cuestionamientos formulados, tanto la Ley Modelo de Insolvencia Familiar como sus proyecciones locales no contemplan disposiciones específicas sobre la vivienda familiar (sin otra protección que la actual regulación del Código Civil y Comercial, y eventualmente leyes locales ${ }^{9}$ ), así como tampoco hay un abordaje de la responsabilidad de los acreedores ${ }^{10}$ por la producción o agravamiento del sobreendeudamiento, de medidas estructurales de prevención del sobreendeudamiento, o abordaje del "crédito responsable" y no solo del "consumo responsable".

Como bien insinúa el título del presente escrito, la Ley Modelo de Insolvencia Familiar o sus proyecciones en el ámbito local en su redacción vigente no son iniciativas conducentes para abordar el sobreendeudamiento de la persona humana y su grupo familiar debido a que por sobre los diseños institucionales subyace una concepción moralista incompatible con una legislación que debe tener por objeto el resguardo de la dignidad de la persona, aun cuando la misma contemple la exclusión de la persona que busca en esta tutela el fraude a los acreedores.

\section{La Ley Modelo de Insolvencia Familiar como una iniciativa regresiva: el proyecto $7482-\mathrm{D}-2010$}

Si bien entendemos que el abordaje del sobreendeudamiento desde la distinción entre "pasivo" y "activo" contiene una

el fraude del deudor quien puede reducir su pasivo mediante acuerdo o sentencia judicial para cancelar con el activo oculto la totalidad de las cuotas pendientes.

9 También resulta interesante recuperar la ley 14.432 de la Provincia de Buenos Aires por la cual se amplía la protección de la vivienda familiar aun sin inscripción. Si bien su constitucionalidad ante la delegación de competencias que implica el art. 75 inc. 12 de la Constitución Nacional se encuentra actualmente pendiente en la Corte Suprema de Justicia de la Nación con dictamen favorable del Procurador Fiscal (COM 15310/2009/CSI "R., L. E. c/ P., G, A, s/ ejecutivo"), lo que implicaría una herramienta de las jurisdicciones provinciales para implementar mecanismos de protección similares, también es un insumo a recuperar a nivel federal.

10 La única responsabilidad del acreedor en el proyecto es por la pretensión falsa o exagerada, o por actos tendientes al agravamiento de la mora durante la producción del proceso, siendo más normas de lealtad procesal similares a las que contemplan los códigos procesales con el instituto de la temeridad y malicia. 
concepción moralista del fenómeno, así como simplifica en extremo un fenómeno complejo en el cual se involucra, por ejemplo, la inducción al consumo mediante prácticas publicitarias y crédito para consumo (Japaze, 2015), o la existencia una sociedad de consumo (Rusconi, 2015), en el caso concreto de la Ley Modelo de Insolvencia Familiar se reafirma esta conclusión cuando observamos el proyecto local 7482-D-2010, un insumo cuyo contenido se proyecta en esta iniciativa de Consumers International.

En este aspecto, como primer elemento a destacar es que el proyecto 7482-D-2010 regula el "sobreendeudamiento pasivo familiar", entendido como una situación pre insolvencia, mientras que la Ley Modelo y sus ingresos en el ámbito nacional son regulaciones de la "insolvencia familiar", siendo la tutela del sobreendeudamiento pasivo secundaria ${ }^{11}$.

Así mismo, el proyecto 7482-D-2010 reafirma esta concepción con la cual discrepamos al excluir al sobreendeudamiento no pasivo (activo) y entenderlo como consecuencia del "consumo irreflexivo e irresponsable del presupuesto que maneja una persona.", acompañado por apelaciones al consumo responsable y reflexivo (art. 2 "Finalidad... Objetivos..."), o en el reconocimiento del principio de "transparencia" restringido a la persona deudora.

\footnotetext{
11 Si bien la definición del sobreendeudamiento en el proyecto 7482-D-2010 desde lo técnico resulta análoga a la insolvencia ("Art. 5. Definiciones: ... Sobreendeudamiento: es la situación en la que se encuentra una persona física no comerciante o su familia que ha contraído deudas en exceso y no puede enfrentar con su patrimonio las mismas, debido a que su pasivo supera su activo.") aún se entiende como una situación pre insolvencia ("("Art. 5. Definiciones... Sobreendeudamiento pasivo: se trata de aquel tipo de endeudamiento consecuencia de situaciones imprevistas o que habiendo sido previstas no han podido evitarse, y que las mismas limitan o condicionan la capacidad de ingresos de una persona física no comerciante bajo riesgo de quedar en condición de insolvencia." ). Con este antecedente, cabe destacar que la Ley Modelo escoge trabajar sobre el concepto de insolvencia, siendo el sobreendeudamiento pasivo como situación pre insolvencia una cuestión secundaria y confundida con la propia insolvencia (ej. "II. Causales de Sobreendeudamiento. Art. 6. Toda persona usuaria de servicios financieros podrá acudir al procedimiento estipulado en la presente ley, siempre que su situación patrimonial sea de insolvencia y la misma fuere producto de alguna de las siguientes causas:").
} 
Por otro lado, salvando esta exclusión del sobreendeudamiento no pasivo, es interesante recuperar el proyecto $7482-$ D-2010 como una propuesta innovadora que establece mecanismos alternativos a los procesos concursales para abordar la situación de sobreendeudamiento, en lo que se destaca el reconocimiento de instancias administrativas prejudiciales de conciliación, mecanismo que permite un mayor acceso al no requerir patrocinio letrado (obligatoriamente) al mismo tiempo que descomprime la carga de tareas en la jurisdicción.

En este sentido, se puede observar que su proyección en la Ley Modelo de Insolvencia Familiar implicó un abordaje regresivo respecto del texto original, en lo cual se destaca:

a) la pérdida del reconocimiento de la relación de consumo, y una redacción deficiente y contradictoria;

b) la modificación del eje de tutela del sobreendeudamiento a la insolvencia, como ya se ha manifestado;

c) se elimina el carácter ejecutivo del acuerdo para requerir necesariamente una homologación judicial ${ }^{12}$;

d) se elimina la obligación del acreedor de comparecer al procedimiento administrativo a efectos de la conciliación ${ }^{13}$;

e) se incorpora en el plan de reestructuración la obligación de disponer medidas para "facilitar o garantizar el pago";

f) se incorpora la facultad judicial de rechazar por ser "inconducente, improcedente o no llenar el cometido y alcance exigido en esta clase de proceso" ${ }^{\prime 4}$;

12 Esta modificación implica mayores costos porque necesariamente requiere patrocinio letrado, mayor actividad jurisdiccional, así como no resultaría ejecutivo en tanto no se homologue.

13 "Art.25. No comparecencia. Si el acreedor no compareciera a la segunda audiencia se fijará una multa según lo establecido en el artículo 47 de la Ley 24.240 de Defensa del Consumidor." (proyecto 7482-D-2010).

14 Si entendemos que estamos tutelando a una persona en situación de vulnerabilidad resulta cuestionable reconocer al juez facultades para cerrar el proceso judicial de modo discrecional cuando la acción resulta objetivamente admisible. En este aspecto, la redacción 
g) se incorpora la imposición de multar o sancionar a la persona deudora por fraude procesal o dolo ${ }^{15}$;

h) se modifica la prohibición de someter las mismas deudas a este procedimiento por una inhabilitación por dos años para instar un nuevo procedimiento administrativo prejudicial de conciliación, así como se elimina la revisión del acuerdo ante incumplimiento no imputable para habilitar un procedimiento nuevo exceptuado de esta prohibición cuando se acredite "estrictamente" el caso fortuito o fuerza mayor;

i) se incorpora la "inconducta" de la persona deudora, en la cual se contempla la obtención de nuevos préstamos ${ }^{16}$ durante la etapa de cumplimiento; y

j) se incorpora expresamente como sanción a la inconducta de la persona deudora en la etapa de cumplimiento la exigibilidad de la totalidad del saldo pendiente ${ }^{17}$.

Finalmente, cuestión no menor, también implicó una afectación de nuestro federalismo al establecerse una instancia administrativa prejudicial de competencia federal, omitida en

habilita a entender que el juez puede evaluar la falta de capacidad de pago para un plan de reestructuración, falta de voluntad del deudor parar hacer el sacrificio necesario, o no satisfacer el "cometido y alcance exigido en esta clase de proceso", concepto indeterminado que incorpora una habilitación para denegar la tutela requerida.

15 Si bien no se tiene intención de defender el accionar fraudulento, además de inclinarnos por su actual regulación en el instituto de la "temeridad y malicia" en los códigos procesales locales, tampoco se observan los motivos para incorporar la multa o sanción (pudiendo generar un agravamiento de la situación económica de la persona) cuando la clausura del proceso frustra esa finalidad fraudulenta e impide una reedición del procedimiento.

16 Además de ser una restricción que entendemos excesiva de la autonomía de la persona, nuevamente encontramos la construcción de causales de "inconducta" o reproche a la negligencia, irresponsabilidad o mala fe del deudor que derivan en un colapso de la situación económica de la persona y su grupo familiar al habilitar a los acreedores a exigir la totalidad de su acreencia pendiente. Así también implica la imposibilidad de instar un nuevo procedimiento administrativo que recupera de modo tácito a la quiebra como la etapa posterior a las instancias contempladas en la iniciativa bajo análisis.

17 La redacción original en el proyecto 7482-D-2010 se limita a establecer el carácter ejecutivo del acuerdo o plan de restructuración de deudas, siendo materia de acuerdo o decisión judicial los efectos de la mora. 
las iniciativas S-0586/12 y S-0030/14, pero manifiesta en el proyecto $S-1061 / 20^{18}$.

Si bien entendemos que el proyecto $7482-\mathrm{D}-2010$ requiere un replanteo de su concepción moralista sobre el fenómeno del sobreendeudamiento, especialmente recuperando la participación del proveedor en la concesión del crédito o financiación para consumo ${ }^{19}$, la iniciativa se presenta como novedosa desde su diseño. En este aspecto, la Ley Modelo de Insolvencia Familiar y sus presentaciones locales se presentan como una iniciativa regresiva respecto de la propuesta original, situación que invita a recuperar el insumo original en el debate parlamentario, así como preocupa que responda a la actividad y lobby de algunas de las asociaciones que representan a los usuarios y consumidores.

\section{La construcción del sujeto de tutela}

Siendo que por medio del presente no nos hemos privado de manifestar nuestras discrepancias con las iniciativas reseñadas, corresponde explicitar los fundamentos por los cuales se propone reformular la concepción desde la cual se aborda la problemática del sobreendeudamiento.

En consecuencia, se destaca que la República Argentina es un estado que ha asumido obligaciones internacionales para con las personas sometidas bajo su jurisdicción, lo que implica la proyección del derecho internacional de los derechos

18 "La autoridad de aplicación de la presente ley será la Unidad de Conciliaciones de Sobreendeudamiento (UCS), la cual será creada a tal efecto, dependiente del Consejo Federal del Consumo....". Si bien se invita a las provincias a adherir a la ley resulta dudosa la suerte del procedimiento administrativo y sus efectos (principalmente la suspensión de los procesos ejecutivos) ante la ausencia de una ley local de adhesión.

19 Si bien nuestra legislación contempla el "principio de préstamo responsable" (Rossi, Rodríguez Bustamante \& Mariani, 2019), también entendemos que hay necesidad de una legislación que sea expresa en sus consecuencias (Sánchez Cannavó, 2018), especialmente ante el sobreendeudamiento del usuario o consumidor (incluyendo también la responsabilidad frente a sus coacreedores perjudicados). 
humanos en el ámbito interno (Rusconi, 2015), especialmente el respeto de la dignidad de la persona como fundamento del estado (Nikken, 1994). En este sentido, encontramos el derecho a un mínimo de propiedad o de acceso al consumo necesario para un nivel de vida adecuado ${ }^{20}$ (Sahián, 2018), estándar que se proyecta como obligación estatal para con las personas bajo su jurisdicción (Rusconi, 2015) " $y$, agregamos, pueden hacer valer ese derecho aun cuando hayan actuado irreflexivamente, si la otra parte estimuló o se aprovechó de ello" (Rossi, 2018:197).

De igual modo, además del carácter convencional de la protección del acceso al consumo por la persona, también encontramos en el plano nacional la Constitución en el artículo 42 reconoce el derecho a un trato digno como fórmula local que recepta a la dignidad de la persona de modo análogo a los tratados de jerarquía constitucional (Rossi, 2018), siendo las leyes del Congreso reglamentaciones que deben respetar este principio rector. En conclusión, entender al sobreendeudamiento como una afectación a la dignidad de la persona, aun por negligencia o irresponsabilidad, no puede implicar (o entenderse) una consecuente renuncia de derechos o de la protección estatal atento al carácter indisponible de la dignidad humana (Nikken, 1994).

Así mismo, en la construcción de las categorías pasivoactivo en el abordaje del sobreendeudamiento, además ocultar la responsabilidad del acreedor en el proceso de colocar crédito a personas sin capacidad de pago en condiciones sustentables en el tiempo en el marco de una relación de asimetría estructural (Rusconi, 2015), también esconde la inacción estatal ante el accionar privado $^{21}$ y la ausencia o insuficiencia de los

20 Como destacan los autores, el derecho humano a la vivienda (Comité DESC, 0.G. N 4), a la salud, a una alimentación adecuada (Comité DESC. 0.G. № 12, pár. 13, y 0.G. № 15, pár. 12 inc. "c"), entre otros derechos interdependientes comprenden el nivel de vida adecuado, 0 vida digna (Ayala Corao \& Rivero, 2019) que tutela el acceso al consumo.

21 Siendo que el mercado del crédito (y el mercado en general) es un espacio en el cual las personas acceden a los bienes y servicios que satisfacen las necesidades y acceden a las condiciones necesarias para una vida digna, el Estado tiene obligaciones de regulación, 
mecanismos para su prevención. En este aspecto, siendo el abordaje del sobreendeudamiento una política pública, definir a su destinatario implica el reconocimiento sujeto en situación de riesgo, vulnerabilidad o desventaja (Giménez Mercado \& Valente Adarme, 2010) pasible de tutela y la exclusión de las restantes ${ }^{22}$.

Por último, aun cuando concurra un endeudamiento negligente o irresponsable por parte de la persona deudora, como bien reconoce la Ley Modelo de Insolvencia Familiar y restantes iniciativas, las consecuencias del sobreendeudamiento se proyectan sobre el grupo familiar. De este modo, también se integra al abordaje del sobreendeudamiento obligaciones estatales específicas respecto de la protección de la familia y sus integrantes, especialmente respecto de niños, niñas y adolescentes $^{23}$, y la necesidad de ponderar las consecuencias de excluir al sobreendeudamiento no pasivo de los mecanismos de rehabilitación sobre el grupo familiar afectado.

Por otro lado, si bien se entiende que clasificar al sobreendeudamiento tiene consecuencias negativas e incompatibles con las obligaciones constitucionales y convencionales del Estado, también destacamos que tanto la Ley Modelo de Insolvencia Familiar, sus proyecciones locales, y la iniciativa 7482-D-2010 expresamente reconocen su finalidad de prevenir la exclusión social.

control y fiscalización respecto de actividades y proveedores que pueden derivar en el sobreendeudamiento de la persona, especialmente cuando se tiene presente las consecuencias del mismo, obligación que impone tanto el estatuto del consumidor (art. 42 C.N., arts. 36, 41-42 y 55 ley 24.240, art. 50 ley 25.065, entre otras) como los tratados de derechos humanos suscriptos por el Estado nacional, ej. el estándar del caso "Ximénez López vs. Brasil" (ColDH, sent. 04-VII-2006, pár. 137, 138 y 141) establece que dentro de la obligación general de garantía de los derechos a la vida (digna) y a la integridad nacen deberes especiales de protección y prevención, determinables en función del caso concreto, incluso en relaciones entre privados.

22 Como se observa, en el abordaje del sobreendeudamiento encontramos además de la necesidad de definir los mecanismos de tutela a la dignidad de la persona una cuestión no menor dada por quienes son las personas que pueden recurrir a los mismos.

23 Ej. el principio del interés superior del niño, niña o adolescente (Convención sobre los Derechos del Niño). 
En este sentido, cabe destacar que la exclusión no implica necesariamente marginalidad, sino también pauperización en la incorporación económica en la sociedad, así como en ámbitos políticos o culturales (Giménez Mercado \& Valente Adarme, 2010), siendo una recepción (limitada) de una lógica centrada en la dignidad de la persona y no solo en su dimensión económica, motivo por el cual se aboga a trabajar legislativamente sobre este principio rector sin las limitaciones de la moralidad o un abordaje desde lo patológico (ej. la intención de defraudar a los acreedores).

\section{Cuestiones pendientes}

Si bien el objeto del presente trabajo es principalmente establecer posición respecto de la concepción desde la que debe abordarse el sobreendeudamiento, también hay otros debates pendientes. En este aspecto, destacamos como cuestiones a resolver:

a) ¿La rehabilitación debe ser una norma autónoma o un proceso concursal especial ${ }^{24}$ ?

b) ¿Cuál es el rol del ministerio público en los procedimientos administrativos y/o procesos judiciales de rehabilitación del sobreendeudamiento ${ }^{25}$ ?

c) ¿Los procedimientos administrativos de conciliación para reestructurar el pasivo deben ser confidenciales ${ }^{26}$ ?

\footnotetext{
24 Entendiendo que responde a un objeto radicalmente distinto la rehabilitación del sobreendeudamiento (el respeto a la dignidad de la persona) nos inclinamos por una norma autónoma, recuperándolo como uno de los principales aportes del proyecto 7482-D-2010, así como de la publicidad de la Ley Modelo de Insolvencia Familiar. Sin embargo, también encontramos propuestas que se inclinan por un abordaje desde el derecho concursal (ej. proyecto 7210-D-2018) que pueden también entenderse como propuestas superadoras.

25 Si bien las iniciativas bajo análisis omiten toda referencia al ministerio público la ley 24.240 (art. 52) introdujo al ministerio público fiscal como un participe más en todo proceso de consumo, ante lo cual una regulación para rehabilitar ante una situación de sobreendeudamiento con pasivo originado en relaciones de consumo se presenta como una instancia para redefinir el alcance de su intervención, así como la oportunidad.

26 Así como podemos entender que es un aspecto propio de la vida privada de la persona deudora que no debe trascender a la esfera pública, también hay que decidir como se
} 
d) ¿Cuál es la protección de la vivienda frente a estos mecanismos de reestructuración del pasivo, o de deudas de consumo ${ }^{27}$ ?

e) ¿Cuál es la responsabilidad de los proveedores por la colocación de crédito o financiación para consumo de modo irresponsable o negligente?

f) ¿Cuál debe ser la consecuencia del uso de los mecanismos de rehabilitación del sobreendeudamiento para defraudar a los acreedores?

g) ¿Cuál es el rol o legitimación de los integrantes del grupo familiar en los mecanismos de rehabilitación del sobreendeudamiento $^{28}$ ?

Así como resaltamos una mora estatal en la sanción de un régimen de rehabilitación frente a situaciones de sobreendeudamiento, también podemos observar que no se agota en la decisión política de sancionar una iniciativa. En este aspecto, la sanción de un proyecto en la materia requiere la implementación de soluciones idóneas, insumos de calidad, y responder al interés de las personas afectadas más que satisfacciones personales (Pérez Bourbon, 2020) o búsqueda de legitimidad en la sociedad.

relaciona esta instancia de negociación con la constatación de incumplimientos a normativa de orden público (ej. ley 24.240) por parte de la autoridad administrativa que motivaría el inicio de las actuaciones sancionatorias.

27 Siendo que la vivienda es un activo de considerable valor económico que también satisface el derecho a la vivienda entendemos que es necesario la discusión respecto a la protección del bien frente al sobreendeudamiento por actividad no empresaria. En este sentido hay cuestionamientos al suministro de crédito o financiación para el consumo sin capacidad de pago cuando el acreedor contempla la existencia de un inmueble (vivienda) como garantía de sus intereses (Sánchez Cannavó, 2018), aun cuando no se constituya una hipoteca, como práctica contraria a las obligaciones del proveedor.

28 En el abordaje del rol o legitimación de las personas que integran el grupo familiar entendemos que encontramos a las mismos como (a) reconocida como víctima de las consecuencias del sobreendeudamiento, (b) parte de la relación de consumo (art. 1 ley 24.240), y/o (c) representante, gestor 0 afectado de la persona sobreendeudada (ej. el rol del hijo/a de una persona mayor jubilada sobreendeudada que asiste económicamente). 


\section{Conclusiones}

A modo de conclusión, el sobreendeudamiento de la persona no se limita a la pérdida de capacidad de pago, sino que implica una afectación a la dignidad de la persona, siendo la rehabilitación y protección de la persona el objeto de cualquier proyecto legislativo en la materia. Así mismo, es necesario renunciar los prejuicios o reproches morales respecto de su causa, sin perjuicio que se reprima el uso fraudulento de estos mecanismos de tutela con la intención de defraudar a los acreedores.

En este aspecto, la Ley Modelo de Insolvencia Familiar y sus ingresos en el ámbito local son iniciativas asistemáticas, con una impronta moralista y que resulta regresiva respecto de sus insumos (proyecto 7482-D-2010), motivo por el cual se considera necesario abandonar esta propuesta cuyo texto se reedita en el tiempo, o bien reformularla contemplando la legislación local, y con la tutela de la dignidad de la persona y su grupo familiar como principio rector.

Si bien hay debates pendientes en la materia, abandonar una perspectiva que entiende al sobreendeudamiento fortuito o culpa de un consumo negligente e irresponsable nos introduce a una materia poco explorada, la responsabilidad del proveedor de crédito o financiación para consumo a personas sin capacidad de pago en condiciones sustentables. De igual modo rápidamente encontramos otras materias poco abordadas seriamente en nuestra actividad legislativa (ej. la usura en las relaciones de consumo o la protección de la vivienda familiar, por mencionar algunos).

Siendo que la intención del presente escrito es la participación en el debate público, especialmente frente una iniciativa regresiva y asistemática que se legitima en la participación de algunas asociaciones de consumidores, esperamos que resulte de alguna utilidad. 